\title{
Penerapan Pemasaran Kain Sutra Melalui E-Business pada Industri Alat Tenun Bukan Mesin Di Kabupaten Wajo
}

\author{
Nur Naninsih ${ }^{* 1)}$, dan Syamsul Alam ${ }^{2)}$ \\ ${ }^{1)}$ Dosen STIE AMKOP Makassar \\ ${ }^{2)}$ Dosen STIE Nobel Indonesia Makassar
}

\begin{abstract}
ABSTRAK
Penerapan pemasaran kain sutra melalui e-business pada Industri Alat Tenun Bukan Mesin (ATBM) di Kabupaten Wajo. Bentuk transaksi e-business yang diterapkan antara lain e-product, e-finnance, e-productin, e-procurement, dan e-payment. Jenis transaksi tersebut terdapat aktivitas-aktivitas yang diterapkan oleh pengusaha/pedagang kain sutra. Tujuan dari makalah ini untuk mengetahui pemasaran kain sutra dengan jenis transaksi e-business yang diterapkan oleh pengusaha/pedagang pada Industri Alat Tenun Bukan Mesin (ATBM). Metode yang digunakan adalah metode literatur dengan sampel pengusaha ATBM sebanyak 40 orang $(3,40 \%)$, pedagang desa sebanyak 5 orang $(10,20 \%$, pedagang kota 4 orang $(19,05 \%)$ dan eskportir sebanyak 2 pengusaha $(33,33 \%)$. Pada penelitian ini, penerapan aktivitas e-business pada pengusaha/pedagang kain sutra dikelompokkan berdasarkan daerah tertentu. Hasil analisis menunjukkan terbentuk tiga daerah pengusaha/pedagang kain sutra yang ditinjau dari penerapan aktivitas e-business. Perbedaan ketiga daerah tersebut terlihat penerapan e-business yang fokus pada sistem pemasok, sistem internal, dan sistem penunjang. Temuan ini mungkin tidak benar secara global, mengingat penelitian e-business yang agak terbatas pada Industri Alat Tenun Bukan Mesin (ATBM), kami menyadari bahwa penelitian ini hanya mewakili tiga daerah yang sifatnya homogen. Akibatnya, kami fokus secara eksplisit pada pemasaran sistem e-business tanpa ketergantungan variabel.
\end{abstract}

Kata Kunci : Pemasaran, Kain Sutra, E-business, dan ATBM

\section{PENDAHULUAN}

Pemasaran kain sutra merupakan bagian terpenting dari usaha pembangunan industri secara menyeluruh, karena merupakan pengamanan dan pendorong peningkatan produksi kain sutra. Dalam kenyataan pemasaran kain sutra menghadapi mata rantai yang rumit. Kenyataan menunjukkan pula bahwa keterlibatan pengusaha pemintalan kain sutra dalam pemasaran hasilnya terbatas, sehingga peningkatan produksi sering tidak diimbangi dengan peningkatan pendapatan, sehubungan rendahnya harga yang diterima, (Naninsih, 2006).

Sejak beberapa dekade yang lalu Kabupaten Wajo terkenal dengan produk kain sutranya, hingga kini menujukkan permintaan kain sutera cukup tinggi. Walaupun jumlah dan kualitasnya belum seperti yang dibutuhkan konsumen. Akan tetapi dewasa ini produk kain sutera Kabupaten Wajo belum mampu secara signifikan meningkatkan pendapatan produsennya. Sementara itu mendapat saingan dari kain sutra impor dan produk dari daerah-daerah lain sehingga kain sutra lokal kurang bisa bersaing. Oleh karena itu permasalahan umum yang dihadapi oleh perusahaan pemintalan kain sutra di Kabupaten Wajo: pertama, adalah belum mampu memenuhi permintaan pasar karena biaya produksi yang tinggi sehingga sebagian besar usaha pemintalan itu mengalami penurunan produksi yang cukup besar bahkan cendrung mengalami kebangkrutan.

Kedua, sehubungan dengan naiknya biaya produksi mengakibatkan kegiatan produksi berkurang sehingga volume penjualan pun mengalami penurunan yang sangat besar. Untuk itu penelitian ini ikut serta membantu mencari jalan keluar bagi para pengusaha pemintalan benang, produsen kain sutera dan meningkatkan kinerja pemasaran, yang selanjutnya akan bermuara pada peningkatan pendapatan para produsen kain sutra, (Naninsih, 2006)

Pada umumnya produktivitas kain sutera Alat Tenun Bukan Mesin (ATBM) di Kabupaten Wajo relatif rendah dengan mutu yang beragam, Banyak faktor penyebab mutu kain sutera seperti mutu benang yang kurang baik, manajemen usaha, kurangnya

*1) Korespondensi penulis: Nur Naningsih, 085298837004, Email : nurnaninsihcani@gmail.com 
pengetahuan dalam proses produksi, permodalan yang dimiliki produsen. Penampilan mutu kain sutera pada akhirnya akan mementukan harga kain sutera di pasaran. Selain itu kondisi ATBM yang terpencar di rumah-rumah penduduk, yang kadangkala jauh dari pusat perekonomian yang mengarah kepeda terbentuknya rantai tataniaga yang panjang. Hal ini terjadi karena adanya peran hirarki dari para pedagang perantara yang cenderung menambah kompleksitas upaya perbaikan mutu kain sutera, (Naninsih, 2006).

Kegiatan pengembangan persuteraan di Kabupaten Wajo dapat ditemui disemua Kecamatan yang ada namun khusus dalam pengembangan persuteraan alam dan produksi benang sutera terkonsentrasi di Kecamatan Sabbangparu dan daerah pengembangannya tersebar di Kecamatan Pammana, Kecamatan Tempe, Kecamatan Bola, Kecamatan Gilireng, dan Kecamatan Majauleng. Sedangkang sentra industri penenunan sutera terdapat di Kecamatan Tanasitolo dan daerah pengembangannya tersebar di Kecamatan Tempe, Kecamatan Majauleng, dan Kecamatan Pammana. (Naninsih, 2006). Kegiatan pengembangan persuteraan baik Industri Hulu yang meliputi persuteraan alam dengan penanaman Tanaman Murbey, Pemeliharaan Ulat Sutera (Bombyx mori, sp), dan produksi kokon serta Industri Hilir yang meliputi pemintalan benang sutera, pertenunan kain sutera, hingga pengembangan deversifikasi produk asal sutera dapat di jumpai di Kabupaten Wajo.

Latar belakang orang Wajo yang dikenal memiliki jiwa enterpreneurship yang tinggi berdampak pada tingginya motivasi mereka untuk mengembangkan komoditas sutera dengan berkreasi dan selalu mencara inovasi baru serta menciptakan berbagai macam produk asal sutera bahkan menjalin hubungan kerjasama dengan pengusahapengusaha Pertekstilan dari Pulau Jawa termasuk designer-designer ternama Indonesia.

Internet telah membuat interaksi bisnis menjadi multi aspek. Sekarang orang bisa melakukan bisnis seperti membeli sesuatu, bertransaksi, dan menjalankan fungsi-fungsi bisnis melalui internet. Konsumen dan pemeliki/pengelola bisnis dapat mendapatkan dan melakukan apa yang mereka inginkan tanpa harus meninggalkan beranjak dari tempat duduk, selama terhubung dengan internet.

Perkembangan $e$-business dalam era informasi menyebabkan terjadinya perubahan kultur bisnis sehingga media elektronik menjadi salah satu media andalan untuk melakukan komunikasi dan bisnis. Penggunaan e-business dalam dapat meningkatkan transformasi bisnis melalui kecepatan, ketepatan, dan efesiensi pertukaran informasi dalam jumlah yang besar (Budianto, 2014). Penerapan e-business juga terbukti dapat meningkatkan transformasi bisnis melalui kecepatan, ketepatan dan efesiensi pertukaran informasi dalam jumlah yang besar (Rahmana, 2009).

Saat ini, karena internet dapat memfasilitasi pergerakan informasi yang cepat dan efesien diantara mitra dagang dengan biaya yang sangat kurang, e-business mulai berkembang secara global, (Emma dan Gergio, 2009). Adopsi teknologi e-business dipengaruhi oleh banyak faktor. Standar industri juga merupakan kekuatan pendorong untuk mendorong perusahaan mengadopsi teknologi e-business (Kula et al., 2003). Namun, ini bisa menjadi penghambat untuk mengadopsi teknologi baru jika pimpinan mampu untuk berinovasi dan untuk menunjukkan keunggulan strategis menggunakan teknologi canggih atau e-business. Sebuah studi yang dilakukan oleh Lacovou et al., (2005) menemukan bahwa kurangnya kesadaran pemilik akan teknologi dan manfaat yang dirasakan adalah faktor utama untuk mengambil alih bisnis elektronik. Faktor lain, menurut Olatokun dan Kebonye (2010) seperti ukuran perusahaan dan jenis usaha juga mempengaruhi pengadopsiannya. Menurut penelitian ini, ukuran, strategi, serta kegiatan perusahaan memiliki pengaruh pada adopsi e-business.

Peningkatan jumlah penggunaan internet berdampak pada pengaruhnya terhadap sektor bisnis dimana internet juga telah mengubah konsep perdagangan tradisional menjadi perdagangan elektronik atau e-business, (Sameyadi, 2016). E-business memungkinkan pertukaran informasi dimediasi elektronik, baik di dalam suatu organisasi dan atau dengan para pemangku eksternal yang mendukung berbagai proses bisnis, (Chaffey, 2010). 
Dalam terminologi yang lebih umum, e-business adalah aktivitas yang dilakukan oleh organisasi individu, atau pihak-pihak terkait untuk mengelola proses bisnis utama untuk menggunakan teknologi komunikasi, komputer, dan yang telah terkomputerisasi sehingga memberikan keuntungan berupa keamanan, fleksibel, optimasi, efesiensi, dan peningkatan produktivitas secara profit (Stoole, 2000; Alter,2002).

Menerapkan aplikasi e-business, UKM dapat secara efektif memperluas ruang lingkup pasar (Hamil dan Gregory, 1997, Wilder et al.1997), membangun pengenalan nama, mengubah rantai pasokan (Rayport dan Sviokla, 1995), dan melacak selera dan preferensi pelanggan (Haynes et al., 1998). Potensi manfaat ini diharapkan menjadi karakteristik yang memotivasi $e$-business yang akan memacu adopsi $e$-business dikalangan pengusaha/pedagang kain sutra. Namun, adopsi e-business oleh UKM telah terbatas (Thong, 1999; Grandon dan Pearson, 2004; Johnson et al., 2007). Para peneliti telah menyimpulkan bahwa manfaat utama dari rovolusi e-business lebih besar, daripada perusahaan yang lebih kecil (Haynes et al., 1998; Jeffcoate et al., 2002).

Sementara itu, ditengah pasar yang semakin kompetitif di seuluh dunia, kebutuhan bisnis kecil untuk mengadopsi e-business hanya untuk bertahan hidup menjadi semakin penting (Chong dan Pervan, 2007). Perusahaan berada di bawah tekanan untuk melakukan sesuatu dengan e-business agar tidak ketinggalan. Tekanan ini dapat datang dari sumber internal atau eksternal (Wymer dan Regan, 2005; Beckinsale et al., 2006) dan telah diidentifikasi sebagai alasan penting untuk investasi e-business (Barnes et al., 2003; Chong dan Pervan, 2007). Usaha kecil dapat mengeluarkan sumber daya mereka yang terbatas untuk menerapkan aplikasi tanpa sepenuhnya memahami peran strategi mereka dalam organisasi (Chong dan Pervan, 2007; Eikebrokk dan Olsen, 2007), akibatnya potensi ketidaksesuaian antara tujuan e-business dan penerapan aplikasi tinggi, mengharapkan pengembangan alat sederhana dan biaya renda untuk membantu pengusaha/pedagang kain sutra mengembangkan pendekatan yang lebih efektif untuk perencanaan $e$-business.

Penerapan pemasaran kain sutra melalui $e$-business dilakukan pendekatan dengan tujuan untuk mengetahui jenis transaksi e-business diterapkan oleh pengusaha/pedagang kain sutra Alat Tenun Bukan Mesin (ATBM).

\section{METODE PENELITIAN}

Metode yang digunakan adalah studi literatur berdasarkan jenis transaksi $e$ business. Populasi obyek penelitian ini terdiri pengusaha kain sutera, pedagang desa, pedagang kota dan eksportir. Populasi pengusaha Alat Tenun Bukan Mesin (ATBM) sebanyak 4.982 unit, populasi pedagang desa sebanyak 49 orang, pedagang kota sebanyak 21 orang dan pedagang antar pulau sebanyak 6 pengusaha.

Mengingat keterbatasan waktu dan biaya maka dalam penelitian ini masing-masing obyek penelitian diambil sampel dengan penetapan jumlah anggota sampel dilakukan secara sengaja dan berjenjang atau sistem acak klaster (Hidayat, dan Sedarmayanti 2002), sehingga diperoleh sampel pengusaha ATBM sebanyak 40 orang $(3,40 \%)$, pedagang desa sebanyak 5 orang $(10,20 \%$, pedagang kota 4 orang $(19,05 \%)$ dan eskportir sebanyak 2 pengusaha $(33,33 \%)$.

1. Identifikasi jenis transaksi e-business pada Pengusaha/Pedagang Kain Sutra Alat Tenun Bukan Mesin (ATBM) berdasarkan literatur berdasarkan literatur.

Pada tahap dilakukan pembuatan kerangka umum e-business melalui studi literatur. Kerangka umum tersebut berisi pembagian jenis transaksi e-business dan aktivitas dari setiap jenis e-business yang terbentuk. Literatur-literatur yang digunakan pada penelitian ini yaitu E-business and e-commerce (Meir, 2009) Analisis proses Adopsi Elektronic Payment (Gandawati, 2011). Kesimpulan jenis transaksi e-business adalah e-product, e-production, e-procurement, e-finance, e-commerce, e-payment.

2. Identifikasi awal jenis transaksi e-business pada Pengusaha/Pedagang Kain Sutra Alat Tenun Bukan Mesin (ATBM) di Kabupaten Wajo. 
Setelah terbentuk kerangka umum e-business, maka dilakukan observasi untuk mengidentifikasi jenis tarnsaksi e-business yang sudah digunakan pada Pengusaha/Pedagang Alat Tenun Bukan Mesin (ATBM) di Kabupaten Wajo. Observasi tersebut dilakukan sebagai identifikasi awal yang dilakukan kepada empat puluh pengusaha/pedagang kain sutra. Penggunaan empat puluh responden bertujuan untuk meningkatkan efesiensi dan mempermudah pelaksanaan penelitian.

Hasil identifikasi awal yang dilakukan, diketahui bahwa jenis transaksi $e$-business tersebut sudah digunakan dalam aktivitas mulai dari proses supllier, proses internal itu sendiri, sampai ketangan konsumen/pelanggan.

Selanjutnya untuk melihat aktivitas-aktivitas dilakukan para pengusaha/pedagang dibuatkan kuesioner yang digunakan untuk melakukan tahap berikutnya. Adapun jenis transaksi e-business dan aktivitasnya seperti berikut :

a. E-Product, yaitu merupakan jenis transaksi atau aktivitas yang dilakukan pengusaha/pedagang kain sutra ATBM, adapun indikatornya antara lain : transfer dokumen dan gambar kepada konsumen, transfer dokumen dan gambar kepada pemasok, penggunaan software pendukung desain online, kolaborasi dengan konsumen secara online, kolaborasi dengan pemasok secara online.

b. E-Production, yaitu proses penggunaan sistem atau akses yang dilakukan pengusaha/pedagang kain sutra ATBM, adapun indikator yaitu : otomatisasi lantai produksi menggunakan sofware, penggunaan sistem informasi dalam mengelola kualitas, pemasok dapat mengases persediaan pengusaha/pedagang, prediksi kuantitas produksi, dan perencanaan jadwal produksi.

c. E-procurement, yaitu proses transaksi melalui akses informasi yang disediakan oleh pengusaha/pedagang kain sutra ATBM, adapun indikatornya yaitu ; pencarian pemasok baru, akses database persediaan barang yang dimiliki oleh pemasok, pembelian barang menggunakan katalog elektronik, standardisasi dan spesifikasi pembelian barang, dan negosiasi kesepakatan mengenai harga dan lainlain dengan pemasok.

d. E-finance, yaitu proses transaksi dengan sistem online baik pencatatan masukan maupun pencatatan pengeluaran atau laporan keuangan. Adapun indikatornya antara lain ; Pencatatan transaksi bisnis, pencatatan hutang, pencatatan pemasukan, perhitungan laba/rugi, dan perhitungan pengeluaran yang dilakukan pengusaha/pedagang.

e. E-commerce, yaitu promosi produk, mengiriman bukti pembelian kepada konsumen secara online, pengelolaan dan penerimaan pesanan konsumen, informasi status ketersediaan produk, dan menawarkan diskon harga kepada pelanggan.

f. E-payment, yaitu transaksi yang dilakukan dengan menggunakan beberapa kemudahan yang diberikan kepada konsumen/pelanggan, adapun indikatornya antara lain ; pembayaran dengan menggunakan kartu kredit, pembayaran dengan menggunakan transfer/online banking, dan pembayaran menggunakan ATM.

\section{HASIL DAN PEMBAHASAN}

A. Penggunaan E-Business pada Pengusaha/Pedagang Kain Sutra Alat Tenun Bukan Mesin (ATBM)

Pemetaan penggunaan e-business dilakukan untuk membentuk kelompok-kelompok daerah yang dijadikan sampel seperti Kecamatan Tempe (kota kecamatan), Kecamatan Majauleng (pedagang desa), dan Kecamatan Pammana (pedagang kota). Daerah yang dipilih memiliki tingkat penggunaan aktivitas e-business pengusaha/pedagang kain sutra ATBM. Setiap aktivitas e-business tersebut dikelompokkan berdasarkan fokus aktivitasnya sebagai supplier, fokus sistemmya kepada pelanggan, fokus sistem pada internal. Sistem supplier merupakan aktivitas e-business yang dilakukan antara 
perusahaan dengan pemasok, sistem internal merupakan aktivitas e-business yang dilakukan untuk menunjang aktivitas internal pengusaha/pedagang, sedangkan sistem pelanggan diidentifikasi dengan aktivitas penggunaan sistem e-business yang diterapkan antara pedagang/pengusaha dengan pelanggan. Kemudian sistem supporting, sistem ini mendukung kegiatan aktivias dari ketiga sistem sebelumnya.

1. Kecamatan Tempe

Penerapan pemasaran kain sutra melalui $e$-business yang terdiri dari pedagang kain sutra Alat Tenun Bukan Mesin (ATBM), pedagang memiliki usaha industri ATBM telah berdiri sekitar 5-10 tahun. Pada umumnya usaha perorangan, pedagang menjual produknya secara langsung kepada pelanggang atau biasa dikenal business to custumer (B2C). Hal ini dibuktikan bahwa telah digunakan aktivitas e-business yang berkaitan dengan koordinasi dengan pelanggaang mengenai desai produk pada jenis transaksi e-product.

Pengusaha/pedagang hanya memproduksi produk ketika ada pesanan dari pelanggan atau make to order (MTO). Pengusaha/pedagang hanya fokus pada

penjualan online (tidak langsung) karena tidak memiliki outlet sendiri sebagai media display produk. Pengusaha/pedagang membuktikan bahwa penerapan pemasaran telah digunakan dengan baik dan telah digunakannya internet banking sebagai media pembayaran dan mempermudah transaksi antar pengusaha/pedagang dengan pelanggan.

Pengusaha/pedagang kain sutra juga sudah mulai menggunakan sebagian aktivitas pada e-finnance seperti pencatatan pemasukan dan transaksi yang dilakukan serta perhitungan pengeluaran. Pengusaha/pedagang sudah melakukan aktivitas pada $e$ procurement yaitu menggunakan aktivitas e-business yang berkaitan dengan pencarian pemasok bahan baku dan melakukan negosiasi kesepakatan harga, dan lain-lain, dengan pemasok.

2. Kecamatan Pammana

Pedagang kain sutra Alat Tenun Bukan Mesin (ATBM) terdiri dari industri/usaha yang sudah berdiri sekitar 5-10 tahun. Pengusaha/pedagang ini telah menerapkan e-business yang fokus pada internal, supplier, dan supporting yang telah lebih baik. Pedagang/pengusaha industri kain sutra ATBM berbentuk usaha perorangan, secara langsung menjual produknya kepada pelanggan (B2C). Pengusaha/Pedagang sudah melakukan aktivitas make to stock atau memproduksi produk untuk dijadikan persediaan, artinya pengusaha/pedagang sudah menerapkan dua sistem, yaitu sistem MTO dan sistem MTS, kedua aktivitas tersebut digunakan untuk menunjang aktivitas produksi yang dilakukan oleh pengusaha/pedagang sehingga dapat meningkatkan persediaan produk kain sutra. Pedagang/pengusaha ini juga sudah menggunakan penjualan produk secara online atau sistem e-business dan untuk menunjang aktivitas internal pedagang/pengusaha sudah menggunakan

e-finnance atau pembayaran kartu debet dan kredit sehingga ada kemudahan konsumen untuk bertransaksi, selain itu penyimpanan produk sebagai persediaan telah menggunakan pencatatan persediaan produk dan asset yang dimiliki oleh pengusaha/pedagang. Pedagang/pengusaha kain sutra telah berkoordinasi dengan pemasok barang dengan baik dengan sistem e-product yaitu transfer dokumen atau gambar yang dinginkan dengan pemasok.

3. Kecamatan Majauleng

Pedagang kain sutra Alat Tenun Bukan Mesin (ATBM) terdiri dari industri/usaha yang sudah berdiri sekitar 1-4 tahun. Pedagang/pengusaha industri kain sutra ATBM berbentuk usaha perorangan. Pengusaha/pedagang melakukan $e$-business produk secara langsung kepada konsumen (B2C) sekaligus pedagang lain atau business to business (B2B). Pengusaha/pedagang melakukan aktivitas sangat sederhana karena pegusaha/pedagang berdomisili mayoritas di Desa. 


\section{KESIMPULAN}

Tujuan dari makalah ini untuk mengetahui penerapan pemasaran kain sutra melalui e-business pada pedagang/pengusaha kain sutra ATBM. Kami menemukan penerapan jenis transaksi e-business pada umumnya memiliki kemampuan yang sama. Keenam jenis transaksi yang diterapkan hanya satu menjadi kelemahan para pedagang/pengusaha yaitu sistem e-production.

Hasil penelitian ini diharapkan dapat menggambarkan tingkat penggunaan $e$ business pada pengusaha/pedagang kain sutra khususnya industri alat tenun bukan mesin (ATBM). Penerapan pemasaran kain sutra melalui e-business cukup baik dan dapat dilakukan pengembangan. Temuan ini mungkin tidak benar secara global, mengingat penelitian $e$-business yang agak terbatas pada industri alat tenun bukan mesin (ATBM), kami menyadari bahwa penelitian ini hanya mewakili tiga daerah yang sifatnya homogen. Akibatnya, kami fokus secara eksplisit pada pemasaran sistem e-business tanpa ketergantungan variabel.

\section{DAFTAR PUSTAKA}

Alter, S., (2002). Information Systems: Foundation of E-Business. Upper Saddle Rive: Prentice Hall.

Budianto, A. E. (2014). Rancangan Bangun Aplikasi E-commerce dengan Pemanfaatan Technology Mobile Computing Sebagai Akslerator Usaha Mikro Kecil Menengah di Kabupaten Malang. Jurnal Teknik Komputer, 16, 63-70.

Barnes, D., Hinton, M. and Mieczkowska, S. (2003), Competitive advantage through eoperations, Total Quality Management and Business Excellence, Vol. 14 No. 6, pp. 659-75.

Beckinsale, M., Levy, M. and Powell, P. (2006), Exploring internet adoption drivers in SMEs, Electronic Markets, Vol. 16 No. 4, pp. 361-70

Chaffey, D., 2011. E-business \& e-commerce management : strategy, implementation and practice. $4 \mathrm{rd}$ ed. England: Pearson

Chong, S. and Pervan, G. (2007), Factors influencing the extent of deployment of electronic commerce for small and medium-sized enterprises, Journal of Electronic Commerce in Organizations, Vol. 5 No. 1, pp. 1-29.

Emma, A.M. \& Georgia, A. (2009). E-Business Adoption in the Banking Industry in Ghana (Doctoral thesis), Department of Business Administration and Social Science, Division of Industrial marketing and University of Technology, Lulea, 39p.

Eikebrokk, T.R. and Olsen, D.H. (2007), An empirical investigation of competency factors affecting e-business success in European SMEs, Information and Management, Vol. 44.No. 4, pp. 36483.

Gandawati, T.S., (2007). Analisis Proses Adopsi Electronic Payment System dengan menggunakan UTAUT model. Makassar: Universitas Gunadarma.

Grandon, E.E. and Pearson, M.J. (2004), Electronic commerce adoption: an empirical study of small and medium US businesses, Information and Management, Vol. 42 No. 1, pp. $197-216$

Hamill, J. and Gregory, K. (1997), Internet marketing in the internationalization of adopters and non-adopters of WWW, Journal of Marketing Management, Vol. 13 Nos 1-3, pp. 9-28.

Haynes, P.J., Becherer, R.C. and Helms, M.M. (1998), Small and mid-sized businesses and internet use: unrealized potential, Internet Research, Vol. 8 No. 3, pp. 229-35.

Hidayat, Syarifudin; dan Sedarmayanti. (2002). Metodologi Penelitian. Bandung : Mandar Maju

Jeffcoate, J., Chappell, C. and Feindt, S. (2002), Best practice in SME adoption of e-commerce, Benchmarking, Vol. 9 No. 2, pp. 122-32.

Johnston, D.A., Wade, M. and McClean, R. (2007), Does e-business matter to SMEs? A comparison of the financial impacts of internet business solutions on European and North American SMEs, Journal of Small Business Management, Vol. 45 No. 3, pp. 354-61

Kula, V. \& Tatoglu, E. (2003). An exploratory study of Internet adoption by SMEs in an emerging market economy. European Business Review, 15(5), 324-333.

Lacovou, C.L, Benbasat I. \& Dexter A.A (2005). Electric Data Inter-change and Small Organization: Adoption and Impact of Technology, Mis Quarterly, Dec 19(4) 465-485. 
Meier, A., \& Stormer, H., (2009) .Springer-Verlag Berlin Heidelberg. 10.1007/978-3-54089328-8.

Naninsih, Nur, (2006). Analisis Pengembangan Pemasaran Tataniaga Kain Sutra di Kabupaten Wajo, Tesis tidak dipublikasikan, UNHAS, 2006.

Olatokun W. \& Kebonye (2010). SMEs and e-commerce adoption in Botswana, International Journal of Emerging technologies and Society, 8(2) pp.44-45.

Rahmana, A. (2009). Peranan Teknologi Informasi Dalam Peningkatan Daya Saing Usaha Kecil Menengah. Seminar Nasional Aplikasi Teknologi Informasi, B, 11-14.

Rayport, J.F. and Sviokla, J.J. (1995), Exploiting the virtual value chain, Harvard Business Review, Vol. 73 No. 6, p. 75.

Sameyadi, (2016).risetdata.com.[Online]Availableat:http://www.risetdata.com/?p=758 [Accessed $09012019]$

Stoole, C., (2000). E-business - Just What is It. http://ebusiness.about.com/industry. Dilihat pada 5 Janurai 2019.

Thong, J.Y.L. (1999), An integrated model of information systems adoption in small businesses, Journal of Management Information Systems, Vol. 15 No. 4, pp. 187-214.

Wilder, C., Caldwell, B. and Dalton, G. (1997), More than electronic commerce, Information Week, pp. 30-40

Wymer, S.A. and Regan, E.A. (2005), Factors influencing e-commerce adoption and use by small and medium businesses, Electronic Markets, Vol. 15 No. 4, pp. 438-53. 